\title{
THE EFFECT OF LOW EARTH ORBIT ATOMIC OXYGEN EXPOSURE ON PHENYLPHOSPHINE OXIDE-CONTAINING POLYMERS
}

\author{
John W. Connell \\ National Aeronautics and Space Administration (NASA) \\ Langley Research Center (LaRC) \\ Hampton, VA 23681-0001
}

\begin{abstract}
Thin films of phenylphosphine oxide-containing polymers were exposed to low Earth orbit aboard a space shuttle flight (STS-85) as part of flight experiment designated Evaluation of Space Environment and Effects on Materials (ESEM). This flight experiment was a cooperative effort between the NASA Langley Research Center (LaRC) and the National Space Development Agency of Japan (NASDA). The thin film samples described herein were part of an atomic oxygen exposure experiment (AOE) and were exposed to primarily atomic oxygen $\left(\sim 1 \times 10^{19}\right.$ atoms $\left./ \mathrm{cm}^{2}\right)$. The thin film samples consisted of three phosphine oxide containing polymers (arylene ether, benzimidazole and imide). Based on post-flight analyses using atomic force microscopy, X-ray photoelectron spectroscopy, and weight loss data, it was found that atomic oxygen exposure of these materials efficiently produces a phosphate layer at the surface of the samples. This layer provides a barrier towards further attack by AO. Consequently, these materials do not exhibit linear erosion rates which is in contrast with most organic polymers. Qualitatively, the results obtained from these analyses compare favorably with those obtained from samples exposed to atomic oxygen and or oxygen plasma in ground based exposure experiments. The results of the low Earth orbit atomic oxygen exposure on these materials will be compared with those of ground based exposure to $\mathrm{AO}$.
\end{abstract}

KEY WORDS: Poly(Arylene Ether Phosphine Oxide)s, Atomic Oxygen Resistant Polymers, LEO Atomic Oxygen Exposure, Phosphine Oxide-Containing Films,

http://setas-www.larc.nasa.gov/esem/AOE.html

This paper is declared a work of the U. S. Government and is not subject to copyright protection in the United States. 


\section{INTRODUCTION}

The Evaluation of Space Environment and Effects on Materials (ESEM) Project, an element of the NASA Space Environments and Effects (SEE) Program, is a cooperative effort between the NASA Langley Research Center (LaRC) and the National Space Development Agency of Japan (NASDA). The ESEM experiments are focused on cosmic dust collection, studies of atomic oxygen effects on materials and space contamination. A portion of this flight experiment, designated the Atomic Oxygen Exposure (AOE) experiment, exposed samples to primarily atomic oxygen $\left(\sim 1 \quad \mathrm{X} \quad 10^{19}\right.$ atoms $\left./ \mathrm{cm}^{2}\right)$. The objective of the AOE experiment, which was flown in August 1997 aboard the space shuttle Discovery (STS-85), was to expose material samples to low Earth orbit (LEO) atomic oxygen (AO) and return them to Earth for subsequent characterization and assessment of short term AO induced effects on select material properties. The material samples discussed herein consist of a colorless poly(arylene ether), designated as $\mathrm{COR}^{1}$, a poly(arylene ether benzimidazole), designated as $\mathrm{TOR}^{1}$ which was used as a coating over Kapton ${ }^{\circledR} \mathrm{HN}$ and a low color polyimide, designated as TOR-RC. All of these polymers contain phenylphoshine oxide groups in the backbone.

Previous work has shown in both ground based $2-5$ and space flight 6,7 exposure experiments that placing phenylphosphine oxide groups into the backbone of organic polymers provides the polymers with a significant increase in resistance to erosion by AO. Other advantages of this approach are that relatively low amounts of phosphine oxide are required ( $\sim 5 \%$ by weight or less) to improve $\mathrm{AO}$ resistance and the incorporation of phosphorus in the form of phenylphosphine oxide groups does not lower the glass transition temperature $\left(\mathrm{T}_{\mathrm{g}}\right)$ or Young's modulus of the base polymer.

During this short term LEO flight exposure experiment, the organic polymeric materials were primarily affected by AO. Other parameters that can affect organic polymeric materials such as ultraviolet radiation (UV), vacuum, thermal cycling, particulate radiation, and micrometeoroids and debris become increasingly important for long term LEO exposures. $\mathrm{AO}$ is known from previous space flight experiments, of both short and long duration, to cause substantial erosion and mass loss of organic polymers ${ }^{8-11}$. Certain perfluorinated polymers, such as poly(perfluoropropylene-co-tetrafluoroethylene) (FEP Teflon ${ }^{\circledR}$ ) have exhibited good resistance to $\mathrm{AO}$ in both ground based and space flight exposure experiments. However, simultaneous exposure to $\mathrm{AO}$ and $\mathrm{UV}$ radiation can dramatically increase the rate of degradation ${ }^{12,13}$. Coatings of inorganic oxides such as aluminum oxide ${ }^{14}$, silicon oxide ${ }^{14}$, chromium oxide ${ }^{15}$ and indium-tin oxide ${ }^{16}$, as well as decaborane-containing polymers ${ }^{17}$, have been shown to protect organic materials from oxygen plasma and/or AO erosion. To provide maximum protection, the coatings need to be $\sim 500-2000 \AA$ thick, relatively uniform and defect free. Recent results from multi-layer thermal insulation (MLI) blankets retrieved from the Hubble Space Telescope exemplify the unpredictable effects that long term space environmental exposure can have on polymeric materials $^{18-23}$. 
NASA has had an interest in improving the AO resistance of polymeric materials for potential applications on the international space station and other LEO based spacecraft. Applications for AO resistant polymers include MLI blanket material (film and thread), externally mounted fabric based structures (softgoods) for storage of tools and equipment for use during extravehicular activities, and tethers for spacecraft and safety tethers for astronauts.

\section{EXPERIMENTAL}

2.1 Starting Materials The general synthesis of phenylphosphine oxide-containing poly(arylene ether)s, ${ }^{2}$ and the poly(arylene ether benzimidazole $)^{24}$ utilized in this study have been previously described. Thin films of these two materials were provided by Triton Systems, Inc ${ }^{1}$. The COR film was approximately 1 mil thick and the TOR sample consisted of a 1 mil film of Kapton $\AA H N$ with a 0.5 mil coating of TOR on one side. TOR-RC is an experimental polyimide, the chemical structure of which cannot be released for publication at this time. It was prepared from a novel diamine and a commercially available aromatic dianhydride. A film was cast from the amide acid and thermally imidized by stage heating through 1 hour at $250^{\circ} \mathrm{C}$ in flowing air. In each case, both control and flight specimens were cut from the same piece of film. The flight specimens were approximately 1 inch wide by 4 inches in length. The control films were stored in a desiccator and were analyzed concurrently with the post-flight specimens. The characterization data determined on the post-flight specimens is relative to that of the control specimens which were stored on Earth for $\sim 1.5$ years.

2.1.2 Flight Experiment Integration/Configuration Prior to integration, the flight specimens were stored in a clean room facility under controlled humidity where they were weighed and photographed. The samples were mounted and integrated into the exposure rack in a controlled humidity clean room environment. The exposure rack was mounted onto a support structure in the space shuttle payload bay. The payload bay was oriented towards the velocity vector (ram direction) and the motorized assembly doors were opened for $\sim 54$ hours of direct ram $\mathrm{AO}$ exposure.

2.1.3 Flight Experiment De-Integration Upon returning to Earth, the Orbiter payload bay was purged to establish the desired environment and the payload doors were opened under clean room conditions. The exposure trays were transported into a Class 100,000 clean room and the flight specimen holders were removed, photographed and sealed in shipping containers and returned to NASA Langley. The AOE tray was visually inspected and the flight specimens were subsequently removed and weighed under conditions identical to those of the pre-flight weighing. One of the post-flight Kapton®HN samples was studied in detail using SEM and AFM to determine surface recession. This was then compared with 
predicted erosion values and those obtained from weight loss data to quantify the AO exposure at $1 \times 10^{19}$ atoms $/ \mathrm{cm}^{2}$.

2.1.4 Polymer Film Characterization Atomic force microscopy (AFM) was performed on a Nanoscope II instrument (Digital Instrument, Inc., Santa Barbara, CA). The samples were rinsed with ethanol and air dried prior to analysis. The AFM was used in the "contact" mode, the cantilever was silicon nitride and all measurements were performed in air. X-ray photoelectron spectroscopic analyses (XPS) were performed by Kalil Characterization and Consulting on a Perkin-Elmer PHI 5300 spectrometer with a magnesium K $\alpha$ X-ray source $(1253 \mathrm{eV})$ operated at $15 \mathrm{kV}$ with an emission current of 20 $\mathrm{mA}$. Typical operating pressures were $<1 \times 10^{-7}$ torr. Analyses were made at a take-off angle of $45^{\circ}$. The carbon $1 \mathrm{~s}$ photopeak was set to $285.0 \mathrm{eV}$ for calibration.

\section{RESULTS AND DISCUSSION}

3.1.1 Polymer Weight Loss/Erosion The chemical structures of the phenylphosphine oxide-containing polymers used in this study are presented in Figure 1. The synthesis<smiles>CC(C)(C)Oc1ccc(C2Nc3ccc(-c4ccc5[nH]c(-c6ccc(Oc7ccc(P(=O)(c8ccccc8)c8ccc(C(C)(C)C)cc8)cc7)cc6)nc5c4)cc3N2)cc1</smiles>

TOR 0.5 mil coated onto 1 mil Kapton®HN film<smiles>CC(C)Oc1ccc(C(C)(C)c2ccc(Oc3ccc(P(=O)(c4ccccc4)c4ccc(I)cc4)cc3)cc2)cc1</smiles><smiles></smiles>

Representative Structure of TOR-RC

Figure 1. Chemical Structures of Phenylphosphine Oxide-Containing Polymers 
and effects of oxygen plasma (asher) exposure on $\mathrm{COR}^{2}$ and $\mathrm{TOR}^{24}$ have been reported. In addition, these materials were part of the Passive Optical Sample Assembly I (POSA 1) flight experiment where samples were mounted to the MIR space station for an eighteen month period and subsequently retrieved ${ }^{7}$. Both COR and TOR exhibited at least an order of magnitude improvement, relative to Kapton ${ }^{\circledR} H N$ and Teflon ${ }^{\circledR}$, in resistance to AO erosion. TOR-RC was designed to incorporate several desirable features into a single polymer, these include low color (low solar absorptance $\alpha$ ), AO resistance, UV resistance and solubility in the imide form (for film processing purposes). This material has not been previously flown on any space flight exposure experiments, but short term ground based exposures to $\mathrm{AO}$ and UV have given promising results 25 .

The film portion of the AOE exposure tray before and after exposure is presented in Figures 2 and 3, respectively. In general, polymeric film samples that have been eroded by LEO AO exhibit a diffuse or frosted appearance easily detected by visual examination. However, visual inspection of the LEO AO exposed phenylphosphine oxide-containing poly(arylene ether) (PPO) films revealed no evidence of frosting and the specimens remained transparent. However, the COR sample exhibited some slight yellowing and the TOR on Kapton ${ }^{\circledR H N}$ sample exhibited a yellow opaque area that can be seen in Figure 3. The initial weights and weight losses of the films after LEO AO exposure are presented in Table 1. The exposed area of the flight samples was approximately 4 square inches. The TOR on

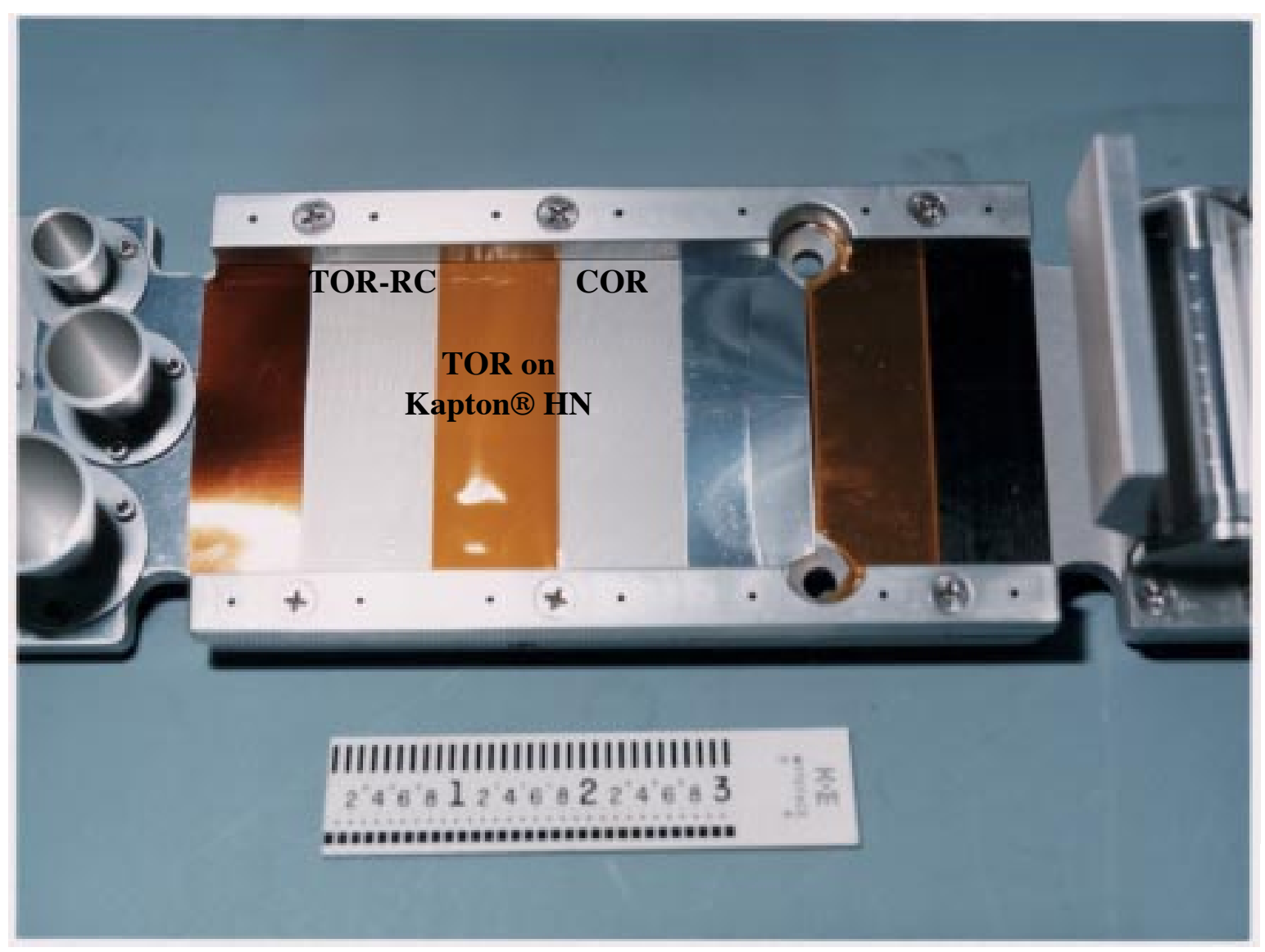

Figure 2. Mounted Films Prior to Integration of AOE Experiment 


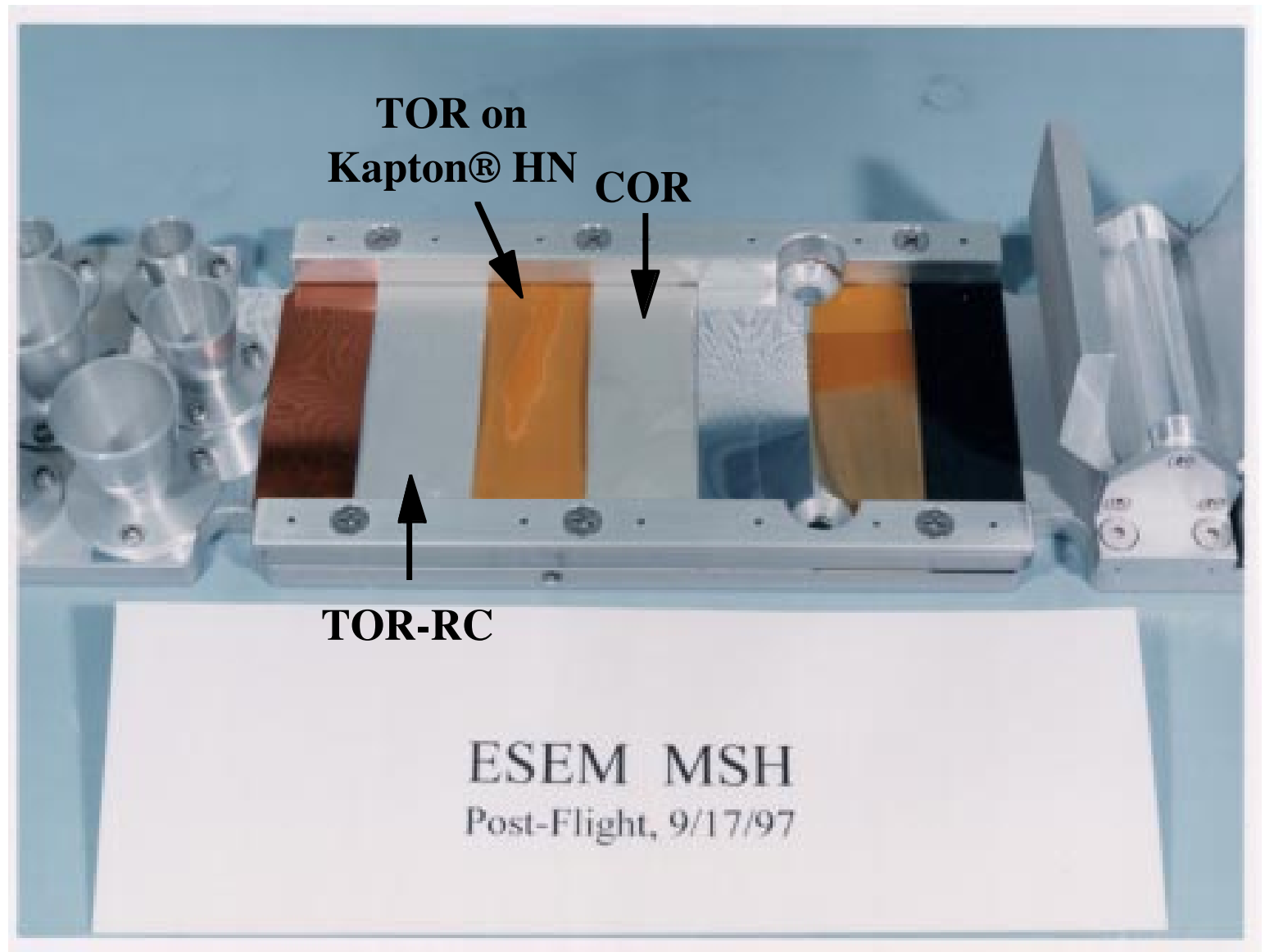

Figure 3. Mounted Films Upon Return from the Flight Experiment

Kapton ${ }^{\circledR H N}$ exhibited a yellow opaque area as can be seen in Figure 3. It was postulated that this area was not adequately coated with TOR and the Kapton®HN exhibited AO erosion giving rise to the frosted appearance. The weight losses exhibited by the films ranged from 0.26 to $1.61 \mathrm{mg}, 0.21$ to $1.77 \%$ by weight. The TOR on Kapton ${ }^{\circledR} \mathrm{HN}$ sample exhibited the highest degree of weight loss. It is likely that most of this weight lost was due to the area on the sample which was not adequately coated with TOR. The COR and TOR-RC lost less than $1 \%$ by weight. The amount of phosphorus by weight in each film is $6.2,4.5$ and $3.6 \%$ for COR, TOR and TOR-RC, respectively. It is important to note that the PPOs do not exhibit linear weight loss rates due to the formation of a phosphate surface layer upon reaction with $\mathrm{AO}^{3}$. Initial weight loss occurs until a sufficient surface layer of phosphate

Table 1. Weight Loss of Phenylphosphine Oxide-Containing

Films after Exposure in LEO

\begin{tabular}{|c|c|c|c|c|}
\hline Film Sample & $\begin{array}{c}\text { Exposure Area, } \\
\text { inch }^{2}\end{array}$ & $\begin{array}{c}\text { Initial Weight, } \\
\mathrm{mg}\end{array}$ & $\begin{array}{c}\text { Weight Loss, } \\
\mathrm{mg}\end{array}$ & Weight Loss, \% \\
\hline COR & $\sim 4$ & 124.29 & 0.26 & 0.21 \\
\hline TOR-RC & $\sim 4$ & 216.66 & 1.38 & 0.64 \\
\hline $\begin{array}{c}\text { TOR on } \\
\text { Kapton }{ }^{\circ H N}\end{array}$ & $\sim 4$ & 91.00 & 1.61 & 1.77 \\
\hline
\end{tabular}


forms on the polymer surface resulting in a significant reduction in the weight loss rate. In comparison, Kapton ${ }^{\circledR} \mathrm{HN}$ and FEP Teflon ${ }^{\circledR}$ undergo linear weight loss rates during exposure to $\mathrm{AO}$.

3.1.2 Surface Analysis With the exception of the TOR on Kapton ${ }^{\circ} H N$ sample, the phenylphosphine oxide containing films exhibited no discernible differences between exposed and control samples by optical microscopy and only minor differences were observed by scanning electron microscopy (SEM). However, analyses by atomic force microscopy indicated that some surface erosion did occur. The TOR on Kapton ${ }^{\circ} H N$ sample exhibited the highest degree of surface roughening after exposure (Figure 4). The COR and TOR-RC samples exhibited similar levels of surface roughening as determined by AFM as shown in Figures 5 and 6, respectively. All exposed samples showed evidence of surface oxide formation (see XPS section). The TOR on Kapton ${ }^{\circledR} H N$ exposed sample exhibited a surface oxide layer of approximately 200 nanometers $(\mathrm{nm})$. The TOR-RC and the

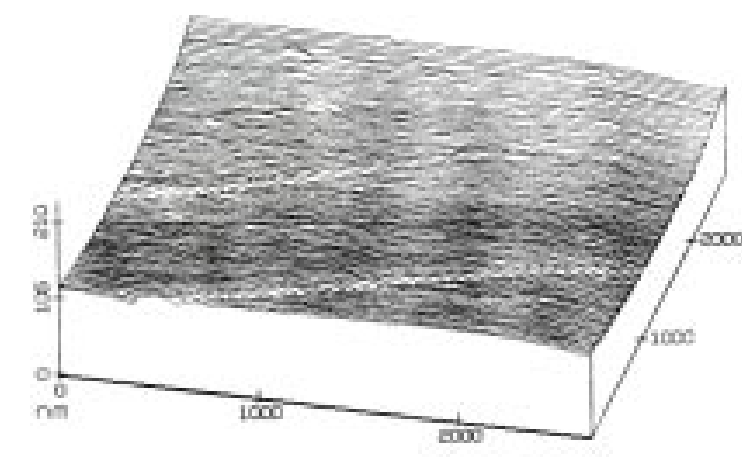

Control

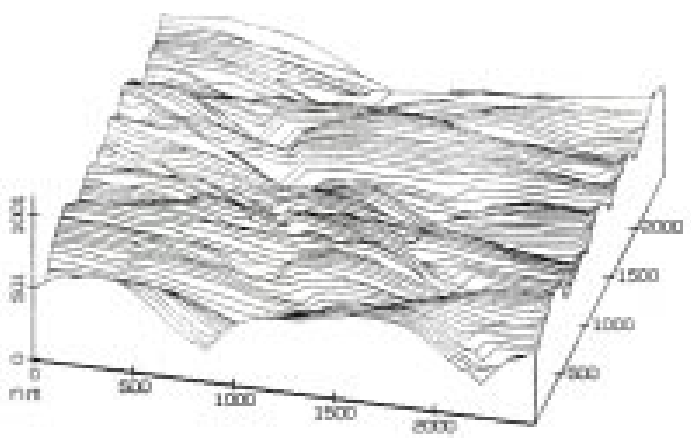

Exposed

Figure 4. AFM Line Plots of TOR coated Kapton ${ }^{\circledR} H N$ before and after exposure.

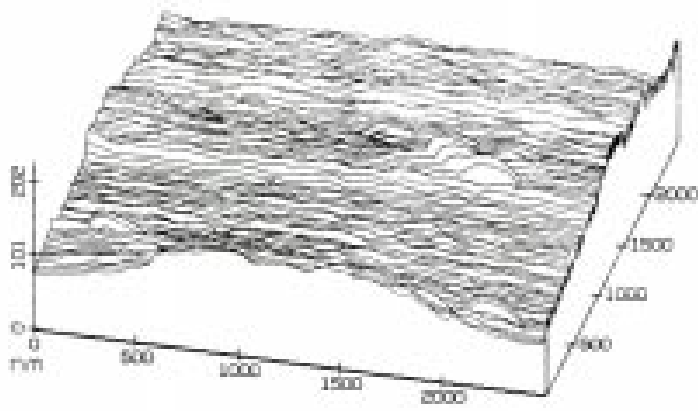

Control

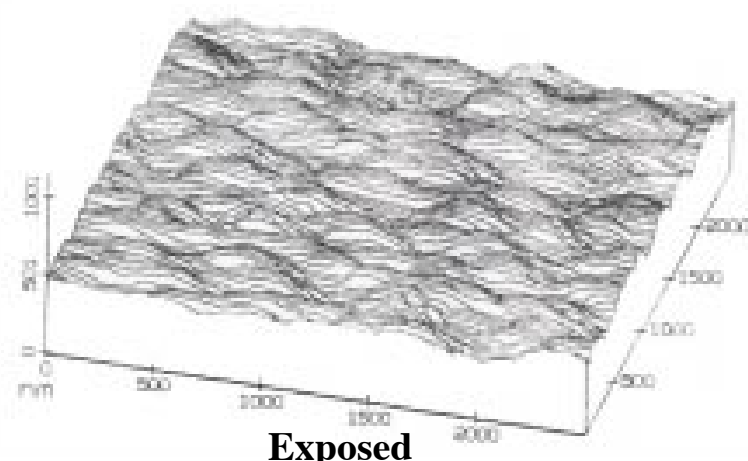

Exposed

Figure 5. AFM Line Plots of COR before and after exposure. 


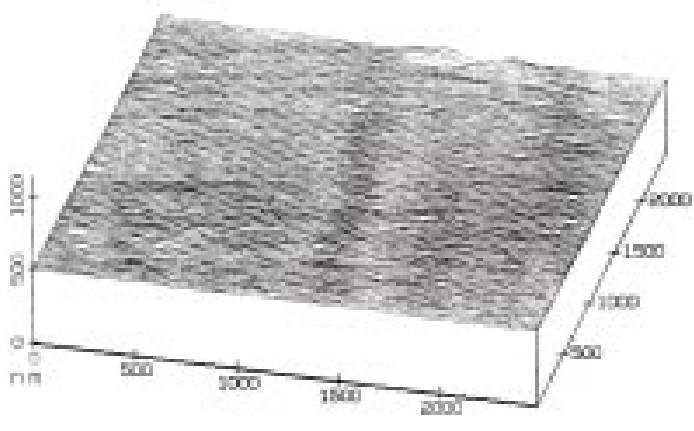

Control

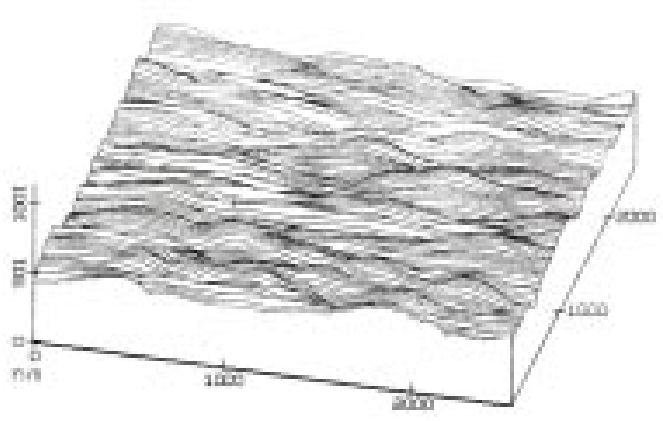

Exposed

Figure 6. AFM Line Plots of TOR-RC before and after exposure.

COR exposed samples exhibited surface oxide thicknesses of 800 and $1700 \mathrm{~nm}$, respectively. No explanation is offered for the differences in thickness of the surface oxide layers. Presumably, initial AO erosion occurs until a sufficient layer of phosphorus oxide (phosphate) is formed on the film surface from the reaction of the oxygen atoms with the phosphorus in the polymers. Once this phosphate layer forms, the erosion rate is reduced dramatically. Therefore, polymers containing phenylphosphine oxide, and possibly other forms of phosphorus, do not exhibit a linear erosion rate.

3.1.3 X-Ray Photoelectron Spectroscopy X-ray photoelectron spectroscopy was performed on each film sample (control and exposed) to determine surface chemistry. A wide scan XPS spectrum was obtained for each sample to insure that all major elements present in the top $5 \mathrm{~nm}$ were detected. Narrow scan XPS spectra were subsequently obtained on each major photopeak detected in the wide scan spectra and on other elements of interest. The carbon, oxygen and phosphorus narrow scan photopeaks were further curvefitted to determine the number of different types of these elements on the surface. The area under the photopeaks was used to determine atomic concentrations.

The binding energy (B. E.) in electron volts (eV) and the atomic concentration (A. Conc.) in percent are listed in Table 2 for all of the phosphine oxide containing films. The ratio of theoretical and observed atomic concentrations for all PPOs are listed in Table 3. Upon examination of the information in these tables several observations are apparent. The carbon content for the control samples is greater than that of the respective exposed specimen. This effect is due to gasification of part of the organic material caused by reaction with AO. In comparing the carbon curve fitted peaks for the control and exposed specimens, it is clear that they differ in both position and intensity indicating that the exposure of these films to AO leads to changes in the carbon functionality on the surface. The oxygen content of the exposed samples is significantly greater than that of the control samples. The exposed films exhibited a higher binding energy for the oxygen indicating a higher oxidation state. The phosphorus content and binding energy of the exposed specimens are greater than that of the respective controls. 
Table 2. XPS Results for Control and Exposed Films

\begin{tabular}{|c|c|c|c|c|c|c|}
\hline \multirow[b]{2}{*}{ Photopeak } & \multicolumn{2}{|c|}{ COR } & \multicolumn{2}{|c|}{ TOR-RC } & \multicolumn{2}{|c|}{ TOR on Kapton ${ } \mathrm{HN}$} \\
\hline & Control & Exposed & Control & Exposed & Control & Exposed \\
\hline C $1 \mathrm{~s}$ & & & & & & \\
\hline A. Conc., \% & 79.7 & 51.9 & 70.7 & 52.0 & 72.6 & 64.8 \\
\hline B. E., eV & 285.0 & 285.0 & 285.0 & 285.0 & 285.0 & 285.0 \\
\hline O $1 \mathrm{~s}$ & & & & & & \\
\hline A. Conc., \% & 9.3 & 30.0 & 16.5 & 21.4 & 16.4 & 23.2 \\
\hline B. E., eV & 532.4 & 533.0 & 532.3 & 533.0 & 532.5 & 533.1 \\
\hline $\mathbf{P} 2 \mathbf{p}^{3}$ & & & & & & \\
\hline A. Conc., \% & 1.7 & 3.0 & 0.6 & 2.1 & 0.9 & 2.9 \\
\hline B. E., eV & 132.5 & 133.8 & 132.7 & 133.3 & 132.6 & 133.6 \\
\hline $\mathbf{N} \mathbf{1 s}$ & & & & & & \\
\hline A. Conc., $\%$ & 1.1 & 1.7 & 4.1 & 3.9 & 4.0 & 5.3 \\
\hline B. E., eV & 399.8 & 402.0 & 400.3 & 400.5 & 400.4 & 400.7 \\
\hline Si $2 p$ & & & & & & \\
\hline A. Conc., $\%$ & 0.7 & 7.4 & 2.4 & 3.8 & 4.2 & 3.3 \\
\hline B. E., eV & 101.9 & 103.4 & 102.1 & 103.1 & 102.2 & 103.7 \\
\hline F1s & & & & & & \\
\hline A. Conc., $\%$ & 7.5 & 5.9 & 5.10 & 16.8 & 1.45 & 0.40 \\
\hline B. E., eV & 688.5 & 688.7 & 688.7 & 688.2 & 688.1 & 688.5 \\
\hline S2p & & & & & & \\
\hline A. Conc., \% & 0.0 & 0.0 & 0.56 & 0.0 & 0.41 & 0.13 \\
\hline B. E., eV & 0.0 & 0.0 & 168.8 & 0.0 & 168.9 & 169.1 \\
\hline
\end{tabular}

Table 3. XPS Atomic Concentration Ratios for Control and Exposed Films

\begin{tabular}{|llll|llll|lll|r|}
\hline \multicolumn{4}{|c|}{ COR } & \multicolumn{4}{c|}{ TOR-RC } & \multicolumn{3}{c|}{ TOR on Kapton ${ }^{\circledR H N}$} \\
\multicolumn{2}{|c|}{ Theory } & Cntrl & Exp. & Theory & Cntrl & Exp. & Theory & Cntrl & Exp. \\
\hline O/C & 0.12 & 0.12 & 0.58 & O/C & 0.17 & 0.23 & 0.41 & O/C & 0.09 & 0.22 & 0.36 \\
N/C & 0.00 & 0.014 & 0.033 & N/C & 0.06 & 0.06 & 0.07 & N/C & 0.11 & 0.05 & 0.08 \\
$\mathbf{P} / \mathbf{C}$ & 0.08 & 0.02 & 0.05 & $\mathbf{P} / \mathbf{C}$ & 0.06 & 0.008 & 0.04 & $\mathbf{P} / \mathbf{C}$ & 0.06 & 0.01 & 0.04 \\
$\mathbf{S i} / \mathbf{C}$ & 0.00 & 0.009 & 0.14 & $\mathbf{S i} / \mathbf{C}$ & 0.00 & 0.03 & 0.07 & $\mathbf{S i} / \mathbf{C}$ & 0.00 & 0.06 & 0.05 \\
\hline
\end{tabular}

Small amounts of nitrogen are present in the COR sample although nitrogen is not a constituent of this material. However, this film was cast from $\mathrm{N}, \mathrm{N}$-dimethylacetamide and residual solvent is the likely source of nitrogen. All of the films were contaminated with silicon from an unknown source and there did not appear to be any obvious systematic variation between control and exposed specimens. The exposed films contained silicon with higher binding energies than the control. Since silicon was present in the control samples at 
concentrations ranging from $0.7-4.2 \%$ and is known to react with $\mathrm{AO}$ to form $\mathrm{SiO}_{\mathrm{x}}$, it may have influenced the behavior of the LEO AO exposed samples to a minor degree.

The atomic concentration ratios for elements of interest are presented in Table 3 . In all cases, the $\mathrm{P} / \mathrm{C}$ ratio for the control is significantly less than the theoretical ratio. This implies that the phosphorus does not reside near the surface in these films and may preferentially orient away from the surface during the film casting and drying process. Relative to the controls, the $\mathrm{P} / \mathrm{C}$ ratio increased after LEO AO exposure, but was still less than the theoretical ratio. In all cases, the $\mathrm{O} / \mathrm{C}$ ratio was significantly higher in the LEO AO exposed films indicating oxygen uptake or loss of carbon or a combination of both. The observation that both the phosphorus and oxygen concentrations in the LEO AO exposed samples increased as did their respective binding energies suggests that a surface layer of phosphate was formed. This observation is consistent with those from both ground-based ${ }^{2-5}$ and $\mathrm{LEO} \mathrm{AO}^{6-7}$ exposure data of polymers containing phenylphosphine oxide. It is unknown if the amount of AO exposure received was sufficient enough to fully form the surface oxide layer or if this process was still in progress.

\section{SUMMARY}

Thin films of phenylphosphine oxide-containing polymers (arylene ether, benzimidazole and imide) were exposed to low Earth orbit AO $\left(\sim 1\right.$ X $10^{19}$ atoms $\left./ \mathrm{cm}^{2}\right)$ aboard a space shuttle flight (STS-85) as part of flight experiment designated Evaluation of Space Environment and Effects on Materials (ESEM). This flight experiment was a cooperative effort between the NASA Langley Research Center (LaRC) and the National Space Development Agency of Japan (NASDA). The films remained clear after LEO exposure with no significant reduction in optical transparency. Changes in the surface chemistry of the exposed films indicated the formation of a phosphate surface layer as observed by XPS analyses. Formation of this surface undoubtedly protected the underlying material from further erosion. Initial erosion due to $\mathrm{AO}$ was observed by AFM. Erosion is necessary to allow sufficient reaction of the atomic oxygen with the phosphorus to form an in-situ phosphate protective coating. The erosion rate of these materials is nonlinear, thus over longer term exposures the weight loss should be significantly less than predicted by a linear extrapolation of this short term AO exposure data. This effect has been substantiated by the eighteen month exposure of the TOR and COR materials aboard the MIR space station as part of the POSA-1 flight experiment ${ }^{7}$.

The use of trade names of manufacturers does not constitute an official endorsement of such products or manufacturers, either expressed or implied, by the National Aeronautics and Space Administration. 


\section{REFERENCES}

1. Samples were provided by Triton Systems, Inc. Chelmsford, MA 01824.

2. C.D. Smith, H. Grubbs, H.F. Webster, A. Gungor, J.P. Wightman and J.E. McGrath, High Perf. Polym., $\underline{3}$ (4), 211 (1991).

3. J.G. Smith, Jr., J.W. Connell and P.M. Hergenrother, Polymer, 35(13), 2834 (1994).

4. J.W. Connell, J.G. Smith Jr. and P.M. Hergenrother, Polymer, $\underline{36}$ (1), 5 (1995).

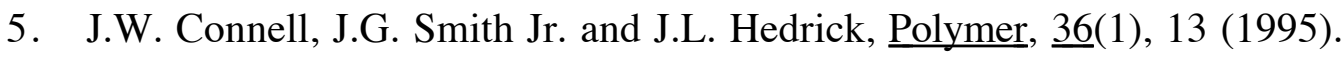

6. J. W. Connell, J.G. Smith, Jr., C.G. Kalil and E. J. Siochi, Polymers for Advanced Technologies, Vol. 9, 11 (1998).

7. J.M. Zwiener, MIR-ISSA Risk Mitigation Flight Experiment RME One Year Report, Oct. 1998.

8. P.N. Peters, R.C. Linton and E. R. Miller, J. Geophys. Res. Lett., 10, 569 (1983).

9. D.E. Bowles and D.R. Tenney, SAMPE J., 23(3), 49 (1987).

10. W.S. Slemp, B.Santos-Mason, G.F. Sykes Jr. and W. G. Witte Jr., AO Effect Measurements for Shuttle Missions STS-8 and 41-G, Vol 1, Sec 5, 1 (1985).

11. LDEF-69 Months in Space. First Post Retrieval Symposium. NASA Conference Publication 3134 Part 2, A. Levine Ed., 1991.

12. L.J. Leger, J.T. Visentine and B.Santos-Mason, SAMPE Quaterly, 118(2), 48 (1987).

13. A.E. Stiegman, D.E. Brinza, M.S. Anderson, T.K. Minton, G.E. Laue and R.H. Liang, Jet Propulsion Laboratory Publication 91-10, May 1991.

14. B.A. Banks, M.J. Mistich, S.K. Rutledge and H.K. Nahra, Proc. $18^{\text {th }}$ IEEE Photovoltaic Specialists Conf.,1985.

15. L.J. Leger, I.K. Spikes, J.F. Kuminecz, T.J. Ballentine and J.T. Visentine, STS Flight 5, LEO Effects Experiment, AIAA-83-2631-CP (1983).

16. K.A. Smith, Evaluation of Oxygen Interactions with Materials (EOIM), STS-8 AO Effects, AIAA-85-7021 (1985).

17. S. Packrisamy, D. Schwam, and M. Litt, Polym. Prepr., 34(2), 197 (1993).

18. P.A. Hansen, J.A. Townsend, Y.Yoshikawa, J.D. Castro, J.J. Triolo and W.C. Peters, Soc. Adv. Matls. and Proc. Eng. Ser., $43(1), 570$ (1998).

19. J.A. Townsend, P.A. Hansen, J.A. Dever and J.J. Triolo, Soc. Adv. Matls. and Proc. Eng. Ser., 43(1), 582 (1998).

20. L. Wang, M. Viens and J.A. Townsend, Soc. Adv. Matls. and Proc. Eng. Ser., 43(1), 594 (1998).

21. C. He and J.A. Townsend, Soc. Adv. Matls. and Proc. Eng. Ser., 43(1), 607 (1998).

22. J.A. Dever, J.A. Townsend, J.R. Graier, A.I. Jalics, Soc. Adv. Matls. and Proc. Eng. Ser., $\underline{43}(1), 616$ (1998). 
23. J.A. Townsend, P.A. Hansen, M.W. McClendon, J.A. Dever, J.J. Triolo, Soc. Adv. Matls. and Proc. Eng. Ser., 43(1), 968 (1998).

24. J.W. Connell, J.G. Smith Jr. and P.M. Hergenrother, Polym. Matls. Sci. and Eng., 70, 492 (1994). High Temperature Properties and Applications of Polymeric Materials, ACS Symposium Series 603, M.R. Tant, J.W. Connell and H. L. McManus, Eds., ACS (1995), pp. 186-199.

25. R. Haghighat, unpublished results, 1997.

\section{Biographies}

John W. Connell is a senior polymer scientist in the Composites and Polymers Branch of the Materials Division at NASA Langley Research Center. He received B.S. and Ph.D. degrees from Virginia Commonwealth University in 1982 and 1986, respectively. Prior to joining NASA LaRC in January 1988, he was a research associate at Virginia Commonwealth University. Since coming to NASA, he has been the author or coauthor of 40 reviewed journal articles, 55 other referenceable publications, 24 U.S. Patents and 1 book. He has received several NASA awards including the prestigious Medal for Exceptional Scientific Achievement in 1997, Richard T. Whitcomb Aerospace Technology Transfer Award in 1998, the Turning Goals into Reality Award in 1998 and co-inventor of the year at NASA Langley in 1994. He received the Arthur S. Flemming Award (Scientific Category) in 1994 and is a member of the Executive Editorial Board of the High Performance Polymers Journal. In his present position, he is responsible for the development of high performance polymers for aerospace applications. 